Rosi Haarer-Becker

Physiotherapeutin,

Verlagsbereichsleiterin Physio- und

Ergotherapie bei Thieme
Uwe Harste

Physiotherapeut,

FiHH das Fortbildungsinstitut in Hamburg

\section{Anklang finden}

_ Der Zukunftsforscher Matthias Horx beschreibt neue Typen, die sich in unserer Gesellschaft entwickeln und bald auch unsere Patienten und Klienten sein werden. Das sind beispielsweise die jungen Creativiteens, die in einem Meer von Möglichkeiten aufwachsen, immer online und auf Ballhöhe sind. Die Gutbürger, die gerne Verantwortung übernehmen und sich ökologisch und sozial engagieren, und die Silverpreneure, die äußerst aktiv altern, sich motiviert mit Erfahrungen und Wissen einbringen und ein neues Altersbild prägen.

_ Die Individuen unserer Gesellschaft werden also mehrheitlich selbstbewusster und selbstbestimmter. Der „Geduldige“ oder gar „Leidende“ unter den Patienten wird rar. Unsere Kunden der Zukunft erwarten guten

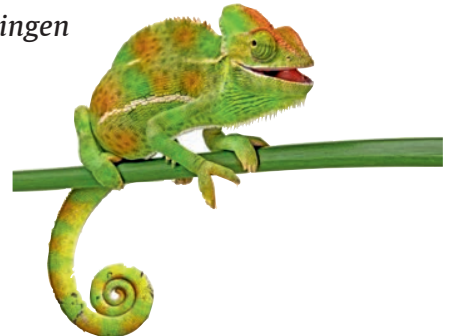
Service und kompetente Therapie, die Symptome nimmt oder lindert. Das ist für sie eine Basisanfor-

derung, eine Selbstverständlichkeit. Begeisterung lösen wir damit nicht oder nur kurzfristig aus. Begeisterung braucht mehr. Hilfe zur Selbsthilfe, Coaching ohne Ratschläge und das sichere Gefühl, als Patient in den besten Händen zu sein - bei einem Profi, der zu einer Berufsgruppe gehört, auf die im Gesundheitssystem nicht verzichtet werden kann.

_ Unter diesem Aspekt möchten wir Ihnen einen Keynote-Vortrag beim 9. physiokongress ans Herz legen. Am Freitag, den 30. Januar 2015, haben wir Karin Probst für Sie eingeladen ( $\odot$ S. 49). Sie ist Business Coach und Stresspräventionsberaterin. Ihr Thema: ,Anklang finden - professionell und stimmig kommunizieren“. Karin Probst mag den Ausdruck "per sonare“. Denn wir können uns mittels Atem, Stimme, Körpersprache und Interaktion auf Zielgruppen einstellen, und das, was dann durchklingt, wird als unsere Persönlichkeit wahrgenommen.

_ Klar gibt es auch jede Menge spannende Fachthemen. Unser zweiter KeynoteReferent, Dr. Thomas Kia, erörtert die Frage: „Das fasziale Netzwerk in Interaktion mit anderen Organsystemen - ist die Faszientherapie eine rein manuell-medizinische Domäne?“

_ Mehr zum Kongress finden Sie auf S. 6 und im Flyer, der dieser Ausgabe beiliegt. Wir hoffen, es ist richtig viel für Sie dabei, und freuen uns auf Sie im Januar 2015. Ihre Programmplaner
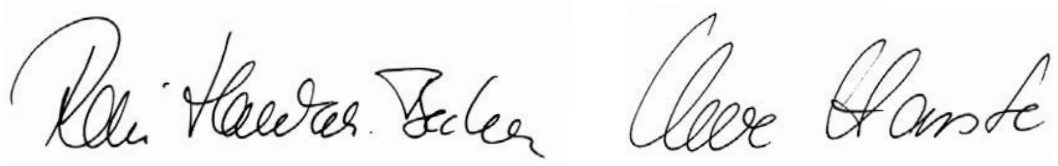

Sich auf die Umgebung optimal einstellen das können nicht nur Chamäleons, sondern auch professionelle Therapeuten.

\section{ZU GEWINNEN}

In jeder physiopraxis werden attraktive Gewinne verlost. Möchten Sie einen ergattern, klicken Sie unter www.thieme.de/physiopraxis auf "Gewinnspiel“.

Und das gibt es in dieser Ausgabe zu gewinnen:

Bücher

3-mal „Überraschend anders: Mädchen \& Frauen mit Asperger“ Seite 39

2-mal „Gewaltfreie Kommunikation - Eine Sprache des Lebens“ Seite 49

3-mal Prometheus Lernposter "Anatomie Knochen und Muskeln“" Seite 52

3-mal „Körpersprache der Kinder“ Seite 56

und außerdem

1 Wiedervereinigungspaket Seite 11 